\title{
Factors affecting in-hospital heat-related mortality: a multi-city case-crossover analysis
}

\author{
M Stafoggia, ${ }^{1} \mathrm{~F}$ Forastiere, ${ }^{1} \mathrm{D}$ Agostini, ${ }^{2} \mathrm{~N}$ Caranci, ${ }^{3} \mathrm{~F}$ de'Donato, ${ }^{1} \mathrm{M}$ Demaria, ${ }^{4}$ \\ P Michelozzi, ${ }^{1}$ R Miglio, ${ }^{5}$ M Rognoni, ${ }^{6}$ A Russo, ${ }^{6}$ C A Perucci ${ }^{1}$
}

- A table on the distribution of acute medical conditions of the patients by age groups and hospital wards is published online only at http://jech.bmj. com/content/vol62/issue3

${ }^{1}$ Department of Epidemiology, Rome E Health Authority, Rome, Italy; ${ }^{2}$ Epidemiological Observatory, Department of Public Health, Local Health Authority, Bologna, Italy:

${ }^{3}$ Epidemiological Services, Grugliasco 5 Health Authority, Turin, Italy; ${ }^{4}$ Epidemiological Services, Regional

Environmental Protection

Agency, Piedmont, Turin, Italy; ${ }^{5}$ Department of Statistical

Sciences, University of Bologna, Bologna, Italy; ${ }^{6}$ Epidemiological Unit, Local Health Authority, Milan, Italy

\section{Correspondence to:}

Francesco Forastiere,

Department of Epidemiology,

Rome E Health Authority, Via

Santa Costanza 53, 00198

Rome, Italy; forastiere@

asplazio.it

Accepted 8 May 2007

\section{ABSTRACT}

Background: Several studies have identified strong effects of high temperatures on mortality at population level; however, individual vulnerability factors associated with heat-related in-hospital mortality are largely unknown. The objective of the study was to evaluate heat-related in-hospital mortality using a multi-city casecrossover analysis.

Methods: We studied residents of four Italian cities, aged 65+ years, who died during 1997-2004. For 94944 individuals who died in hospital and were hospitalised two or more days before death, demographics, chronic conditions, primary diagnoses of last event and hospital wards were considered. A city-specific case-crossover analysis was performed to evaluate the association between apparent temperature and mortality. Pooled odds ratios $(\mathrm{OR})$ of dying on a day with a temperature of $30^{\circ} \mathrm{C}$ compared to a day with a temperature of $20^{\circ} \mathrm{C}$ were estimated with a random-effects meta-analysis.

Results: We estimated an overall OR of 1.32 (95\% confidence interval: $1.25,1.39)$. Age, marital status and hospital ward were important risk indicators. Patients in general medicine were at higher risk than those in high and intensive care units. A history of psychiatric disorders and cerebrovascular diseases gave a higher vulnerability. Mortality was greater among patients hospitalised for heart failure, stroke and chronic pulmonary diseases.

Conclusions: In-hospital mortality is strongly associated with high temperatures. A comfortable temperature in hospitals and increased attention to vulnerable patients during heatwaves, especially in general medicine, are necessary preventive measures.

After the disturbing increase in number of deaths observed in several European countries during the summer of $2003,{ }^{12}$ a considerable research effort is being conducted to evaluate the impact of the high temperature-related mortality, ${ }^{3-5}$ the geographical differences in the impact, ${ }^{6}$ the development of watching/warning systems ${ }^{78}$ and the specific individual social and clinical factors that confer susceptibility to heat stress, especially among the elderly. ${ }^{9}$ People living alone and of low socioeconomic status seem to be particularly vulnerable. ${ }^{10}{ }^{11}$ The research efforts are also intended to guide acute medical care, public health interventions and social services during heatwaves.

We have recently reported the results of a multicity, population-based, case-crossover analysis conducted in four Italian cities to evaluate the overall impact of heat-related mortality and the specific subpopulations that are vulnerable to hot weather. ${ }^{9}$ Extensive record linkage procedures were used to characterise mortality records for subjects aged $35+$ with respect to previous morbidity. We found that the elderly, women, widows/widowers and subjects with psychiatric disorders, depression, heart conduction disorders and previous stroke are at higher risk of dying during extremely hot days. Unexpectedly, we found that the increase in mortality caused by high temperature was not limited to individuals residing in private or nursing homes (as suggested in the literature ${ }^{12}$ ) but also among those in hospital. This finding has been explained by the lack of air conditioning facilities in Italian hospitals during the period of the study.

The results of the previous study have public health implications. If a large proportion of heatrelated mortality occurs among already hospitalised people, public health activities during heatwaves should not be concentrated solely on susceptible populations at home but also towards people who are already under medical care in hospitals. A study conducted in France during summer 2003 clearly suggested that hospitalacquired heat stroke is a nosocomial disease. ${ }^{13}$ Therefore, it is important to understand the specific vulnerability factors for those individuals who are already in hospital during heatwave events.

The aim of the present study was to evaluate hospital-related factors, demographic and clinical characteristics that increase heat-related mortality among hospitalised patients during a heatwave. In the present study, the dataset of the largest city has been extended to include 2004, we have focused on elderly subjects (65+ years) and the analysis has been restricted to patients who were already hospitalised two days before death, and thus were inside a care facility when exposed to hot weather.

\section{MATERIALS AND METHODS}

\section{Subjects' data}

The original study has been conducted among 205019 subjects aged 35+ years, residing and dying in four Italian cities from all non-injury causes (International Classification of Diseases, 9th revision, ICD-9: 1-799) in the following periods: 20003 in Bologna, 1999-2003 in Milan, 1998-2001 in Rome and 1997-2003 in Turin. ${ }^{9}$ We have now extended to 2004 the data collection for Rome so as to encompass 267611 individuals. Since the previous analysis showed that heat-related mortality was clearly present among the elderly, for the present study we have restricted the analysis to 228596 subjects aged 65+ years. 
Data sources were the Regional Registers of Causes of Death (causes of deaths already coded) and the Regional Hospital Discharge files (which include hospitalisations in public and private hospitals nationwide of all resident citizens). A record linkage was performed (using the individual fiscal code) to attribute hospitalisation history of the past two years for each deceased subject. We collected information on gender, age, marital status, median income of the census block of residence and location of death. The information on income was used to attribute to each subject a socioeconomic level according to one of four categories from the city-specific distribution: up to the 20th percentile, 20 th-50th percentile, 50 th-80th percentile and 80th-100th percentile. These percentiles were chosen to better discriminate between extreme and intermediate social conditions. The use of city-specific distributions, rather than the cumulative one, was motivated by the city-specific analysis in the first stage (see below) and the need to better represent local situations. Given the administrative nature of our sources, we could not collect other individual factors, like tobacco smoke or alcohol consumption.

Considering location of death, date of hospitalisation and date of death, we distinguished between those who died in a nursing home, died out of hospital, died in hospital and were hospitalised during the last two days before death, died in hospital and were hospitalised two or more days before death. For the latter subgroup, we considered the type of the hospital (public under the Italian National Health Service (NHS), private but with a financial agreement with the NHS, and entirely private) and the specific hospital ward where the patient was present two days before death (general medicine, medical or surgical wards with low-moderate care load, medical or surgical wards with high care load, intensive care units).

For each individual, all hospital admissions during the two years preceding death (excluding the last 28 days) were selected, considering both primary causes of admission and secondary contributing diagnoses. Each subject was classified according to having been hospitalised for a list of 26 groups of diagnoses chosen by adapting the Elixauser list of comorbidities. ${ }^{14}$ The 28 day window was applied to distinguish between chronic conditions and a sudden deterioration of health in the few weeks or days before death.

Finally, we evaluated the acute clinical conditions that contributed to the fatal outcome considering a selected group of conditions noted as primary diagnoses on the hospitalisation records during the last 28 days. In most of the cases, the hospitalisation record was the last one on which the fatal outcome was recorded.

\section{Environmental data}

Daily information on temperature, humidity and barometric pressure were provided by the Italian Air Force Meteorological Service. The average of the current and the preceding day mean apparent temperature (lag 0-1) was used as the exposure variable $^{15}$ on the basis of previous investigations. ${ }^{12}$ Apparent temperature is a composite index which combines information from air temperature and humidity, and better takes into account the actual physical stress in the warmer days. We also collected daily mean data on particulate matter with aerodynamic diameter lower than $10 \mu \mathrm{m}, \mathrm{PM}_{10}$ (lag 0-1), and ozone (daily maximum 8-hour running mean, lag 0) from the regional environmental protection agencies, since air pollution has been associated with short-term increase in mortality (a separate report on air pollution and mortality is in preparation).

\section{Data analysis}

The methods for data analysis have been extensively explained elsewhere. ${ }^{9}$ Briefly, the association between apparent temperature and daily mortality was analysed using the case-crossover approach, ${ }^{16}$ with the time-stratified strategy for the selection of control days. ${ }^{17}$ Each case-day was compared with a set of control-days matched on the year, month and day of the week by fitting a city-specific conditional logistic regression model, and the results were finally pooled in a random-effects metaanalysis. ${ }^{18}$

Since the relation between temperature and mortality turned out to be J-shaped, we first explored the concentration-response function by adapting a cubic penalised spline of apparent temperature for each centre, and then approximated the smooth curves with three straight lines so as to simplify the relation while at the same time taking into account the main curvature of the function. The models also controlled for $\mathrm{PM}_{10}$, influenza epidemics (defined on the basis of the weekly estimates of influenza incidence, as reported by the Italian NHS), population decrease during the vacation periods, holidays and barometric pressure, while time-trends and day of the week were controlled for by design. No need to control for ozone was evident from exploratory analyses.

The results are expressed as pooled odds ratios (OR), with $95 \%$ confidence intervals $(95 \% \mathrm{CI}$ ), of dying on a day with a $30^{\circ} \mathrm{C}$ apparent temperature relative to a day with a $20^{\circ} \mathrm{C}$ apparent temperature. We investigated the potential effect modification of sociodemographic characteristics, hospital characteristics, chronic and acute clinical conditions by calculating ORs in the subgroup of interest and in the reference category. Since possible effect modification may be due to age differences of the compared subgroups, all the analyses were repeated with adjustment for age (three groups, 65-74, 75-84 and $85+$ ) using as standard weights the frequency distribution of age in the whole population. The relative effect modification (REM) index, calculated as the ratio between the OR of the specific category by the OR of the reference category, provides a useful measure of effect modification together with its $p$ value.

\section{RESULTS}

Rome is located in central Italy and it is the largest city in the study; Turin, Milan and Bologna are located in northern Italy, are smaller than Rome and have slightly different meteorological conditions. Environmental data and city-specific mortality counts by place of death are reported in table 1 .

Rome displays the most concentrated distribution of mean apparent temperature, while Bologna and Milan the most dispersed. The difference between apparent temperature in casedays and the respective control-days, considered the relevant exposure indicator in case-crossover studies, ${ }^{19}$ is also reported. We computed the differences between all control-days and their case-day so that the different number of control-days (three or four) was considered. The four distributions are centred on zero, and show little difference in the interquartile ranges between cities, with Rome having slightly less variability. At the bottom of the table, the city-specific numbers of subjects are shown. Out of a total of 228596 individuals older than 64 years, 10041 died in a nursing home (information available for Milan and Turin only), 96451 died out of hospital, 27155 died within the two days after being hospitalised, and 94944 died two days or more after hospitalisation (five missing information for Bologna).

The overall OR for the total population of $65+$ years of the four cities was 1.40 (95\% CI: 1.29 to 1.51$)$ —namely, there was a 
Table 1 Environmental variables and number of deaths (age 65+ years) in the four Italian cities

\begin{tabular}{|c|c|c|c|c|}
\hline & Bologna (2000-3) & Milan (1999-2003) & Rome (1998-2004) & Turin (1997-2003) \\
\hline \multicolumn{5}{|l|}{ Environmental variables } \\
\hline \multicolumn{5}{|l|}{ Apparent temperature $\left({ }^{\circ} \mathrm{C}\right)$} \\
\hline Mean (SD) & $13.8(10.0)$ & $14.3(10.4)$ & $15.7(8.6)$ & $11.9(9.4)$ \\
\hline Max & 33.9 & 37.5 & 33.3 & 33.2 \\
\hline \multicolumn{5}{|l|}{ Percentiles } \\
\hline 25th & 5.0 & 5.4 & 8.4 & 3.7 \\
\hline \multicolumn{5}{|c|}{$\begin{array}{l}\text { Difference of apparent temperature between } \\
\text { "case-day" and "control-days" }\left({ }^{\circ} \mathrm{C}\right)\end{array}$} \\
\hline Mean (SD) & $0.2(4.8)$ & $0.1(4.8)$ & $0.1(4.5)$ & $0.1(4.8)$ \\
\hline Min & -21.1 & -23.6 & -16.6 & -20.9 \\
\hline Max & 21.1 & 23.6 & 16.6 & 20.9 \\
\hline \multicolumn{5}{|l|}{ Percentiles } \\
\hline Mean (SD) & $1016(7.4)$ & $1016(7.4)$ & $1015(6.6)$ & $1017(7.6)$ \\
\hline \multicolumn{5}{|l|}{$\mathrm{PM}_{10}\left(\mu \mathrm{g} / \mathrm{m}^{3}\right)$} \\
\hline Mean (SD) & $50.4(31.7)$ & $56.7(37.4)$ & $47.3(19.8)$ & $65.5(34.8)$ \\
\hline \multicolumn{5}{|l|}{ Ozone $\left(\mu \mathrm{g} / \mathrm{m}^{3}\right)$ (April to September) } \\
\hline Mean (SD) & $102.2(35.9)$ & $117.4(42.6)$ & $110.8(30.5)$ & $100.8(39.0)$ \\
\hline \multicolumn{5}{|l|}{ Population under study } \\
\hline No of deaths $(\%)$, age $65+$ years & $14838(100.0)$ & $45818(100.0)$ & $123484(100.0)$ & $44456(100.0)$ \\
\hline \multicolumn{5}{|l|}{ Location of death } \\
\hline Nursing home & - & $6868(15.0)$ & - & $3173(7.1)$ \\
\hline Out of hospital & $6105(41.1)$ & $18354(40.1)$ & $59524(48.2)$ & $12468(28.1)$ \\
\hline In hospital ( $<2$ days) & $2870(19.4)$ & $4422(9.6)$ & $10937(8.9)$ & $8926(20.1)$ \\
\hline
\end{tabular}

$40 \%$ increase in mortality at $30^{\circ} \mathrm{C}$ when compared with $20^{\circ} \mathrm{C}$ after adjustment for several factors. Figure 1 shows how the association between temperature and mortality varies by location of death, with the highest OR recorded for subjects in nursing homes or in hospital for less than two days (OR: 1.63; $95 \%$ CI: 1.42 to 1.86 , and OR: $1.46 ; 95 \%$ CI: 1.26 to 1.70 , respectively) and an intermediate effect was estimated for outof-hospital deaths (OR: 1.40; 95\% CI: 1.26 to 1.55), whereas subjects hospitalised for more than two days who died in hospital had an OR of 1.32 (1.25 to 1.39), which is the lowest effect but still highly statistically significant.

All the additional analyses were restricted to the last subgroup of subjects already within a hospital when exposed to the lagged apparent temperature.

Table 2 shows the results of the subgroup analysis by sociodemographic and hospital characteristics.

Unadjusted and age-adjusted ORs are reported, with the summary index of relative effect modification (REM) and $p$ values. Gender does not seem to play an important role in the temperature-mortality association in this population (although a slightly higher risk is present among women), while age increases the risk of heat-related death with a higher odds ratio (1.50; 95\% CI: 1.35 to 1.66$)$ found for those $85+$ years. Not married, divorced and widowed patients were at higher risk of dying from heat stress (OR: 1.42) than married people (OR: 1.16), and the difference remains when adjusting for age. Income shows a uniform effect among the four categories. The risk of dying was not modified by the type of hospital, whereas the specific hospital ward was a significant effect modifier in the analysis not adjusted for age, with subjects in general medicine having a higher risk of death (OR: 1.40) than those hospitalised in other wards, suggesting a reduction of the risk in the more specialised departments and intensive care units. However, this pattern was less clear when adjusting for age.

The simultaneous effect modification by age (three classes) and hospital ward is reported in table 3 .

In all age groups, subjects in general medicine were always at high and statistically significant risk of dying due to high temperature. However, people younger than 85 years were less affected by high summer temperatures when they were admitted in wards other than general medicine and the effect becomes nil in intensive care units. These differences, however, do not hold for the $85+$ years age group, where the point estimate for those in intensive care units (a total of 1505 subjects) is the highest (OR: 1.82; $95 \% \mathrm{CI}: 1.20$ to 1.77 ). The online table reports the distribution of acute medical conditions of the patients by age groups and hospital wards. The relative frequencies of various conditions, especially acute myocardial infarction and cerebrovascular diseases, are different by ward type, but these differences are similar across the age groups investigated.

Table 4 shows the unadjusted and age-adjusted ORs for 26 groups of diagnoses figuring as the primary or secondary cause of hospital admission in the two years before death, with the exclusion of the last four weeks. The REM indicates the comparison between the subjects with the specific condition and those without it.

Psychiatric disorders and cerebrovascular diseases are the most important effect modifiers with ORs of 2.05 (1.44 to 2.93) 
Table 2 Risk of dying on days with a mean apparent temperature of $30^{\circ} \mathrm{C}(\operatorname{lag} 0-1)$ versus days with a temperature of $20^{\circ} \mathrm{C}$ among people age $65+$ years dying in hospital and already in hospital two days before death: effect modification by age, gender, socioeconomic characteristics, hospital ward and type of hospital

\begin{tabular}{|c|c|c|c|c|}
\hline & No (\%) & $\begin{array}{c}\text { OR (95\% CI)** } \\
\text { (unadjusted) }\end{array}$ & $\begin{array}{l}\text { OR (95\% Cl)* } \\
\text { (age-adjusted) }\end{array}$ & $\begin{array}{l}\text { REM index } \dagger \\
\text { (p value) }\end{array}$ \\
\hline Total (65+ years) & $94944(100)$ & $1.32(1.25$ to 1.39$)$ & $1.32(1.25$ to 1.39$)$ & $(-)$ \\
\hline \multicolumn{5}{|l|}{ Age (years) } \\
\hline $75-84$ & $38938(41)$ & 1.26 (1.13 to 1.39$)$ & 1.26 (1.13 to 1.39$)$ & $1.02(0.784)$ \\
\hline $85+$ & $29243(31)$ & $1.50(1.35$ to 1.66$)$ & $1.50(1.35$ to 1.66$)$ & $1.22(0.005)$ \\
\hline \multicolumn{5}{|l|}{ Gender } \\
\hline \multicolumn{5}{|l|}{ Marital status } \\
\hline Married & $17083(47)$ & 1.16 (1.01 to 1.34$)$ & $1.16(1.02$ to 1.32$)$ & $1.00(-)$ \\
\hline Not married/widowed/divorced & $18974(53)$ & 1.42 (1.27 to 1.57$)$ & $1.38(1.24$ to 1.54$)$ & $1.19(0.040)$ \\
\hline \multicolumn{5}{|l|}{ Income (area level) } \\
\hline 20th percentile & $20756(22)$ & 1.33 (1.09 to 1.63$)$ & $1.35(1.10$ to 1.66$)$ & $1.00(-)$ \\
\hline 20th-50th percentile & $29915(32)$ & 1.35 (1.20 to 1.52$)$ & $1.36(1.23$ to 1.51$)$ & $1.01(0.926)$ \\
\hline Semi-public & $11742(16)$ & $1.29(1.11$ to 1.49$)$ & $1.31(1.13$ to 1.51$)$ & $0.98(0.802)$ \\
\hline Private§ & $9570(13)$ & $1.35(1.14$ to 1.60$)$ & $1.35(1.13$ to 1.60$)$ & $1.01(0.917)$ \\
\hline \multicolumn{5}{|l|}{ Ward of the hospital } \\
\hline General medicine & $53481(56)$ & 1.40 (1.31 to 1.51$)$ & $1.40(1.30$ to 1.51$)$ & $1.00(-)$ \\
\hline Low-care load & $24299(26)$ & 1.30 (1.17 to 1.45$)$ & $1.35(1.21$ to 1.50$)$ & $0.96(0.531)$ \\
\hline High-care load & $5791(6)$ & $1.10(0.89$ to 1.35$)$ & $1.13(0.90$ to 1.41$)$ & $0.80(0.067)$ \\
\hline Intensive care & $10573(11)$ & $1.08(0.92$ to 1.26$)$ & $1.24(1.03$ to 1.50$)$ & $0.88(0.236)$ \\
\hline
\end{tabular}

${ }^{*}$ Odds ratio (OR) and $95 \%$ confidence intervals (Cl). Results in italics are from random effects models.

$\uparrow R E M$, relative effect modification index is calculated as the ratio between the specific $O R$ and the $O R$ from the reference category (from the age-adjusted model). \#Milan and Turin only. §Bologna, Milan and Rome only.

and 1.50 (1.32 to 1.70), respectively, and $p$ values of REM Indexes lower than 0.10 . In addition, a previous diagnosis of diseases of the central nervous system (other than paralyses), heart conduction disorders and hip fracture seem to confer a higher vulnerability, although the p values for REM are far from significant. On the contrary, hospitalised subjects with a previous history of cancer or with fluid and electrolyte disorders

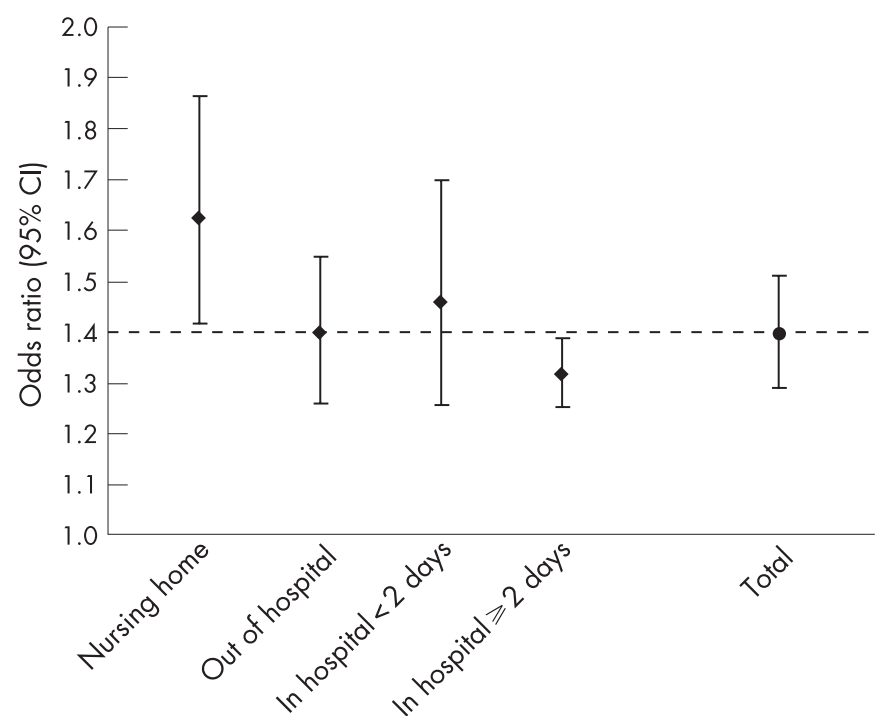

Figure 1 Risk of dying in the 65+ age group on days with a mean apparent temperature of $30^{\circ} \mathrm{C}$ (lag $\left.0-1\right)$ versus days with a temperature of $20^{\circ} \mathrm{C}$, by place of death. Combined results for the four Italian cities. have a lower relative risk of dying during hot days (OR: 1.18; 95\% CI: 1.03 to 1.36 and OR: $0.94 ; 95 \%$ CI: 0.63 to 1.41 , respectively). No noticeable effect modification was detected for the other conditions.

When we evaluated the role of the acute conditions leading to death (table 5), heart failure (OR: 1.69; 1.34 to 2.14), cerebrovascular diseases (OR: $1.59 ; 1.37$ to 1.84 ) and chronic pulmonary diseases (OR: $2.48 ; 1.50$ to 4.09 ) emerged as strongly associated with heat-related mortality, with REM indexes statistically significant at the 5\% level. Similarly, changes of pulmonary circulation, which is usually related to lung diseases and failure of the right side of the heart, were also associated with increase in mortality related to high temperature.

\section{DISCUSSION}

The study confirms that high summer temperatures are associated with an increase in mortality among patients already in hospital at the time of the heat stress. In the age group 6584 years, the hospital ward is an important effect modifier as higher heat-related mortality was found in general medicine wards, whereas no increased risk due to heat was found in intensive care units. On the other hand, for those aged 85+ this effect modification was not present. The susceptibility factors identified in this high-risk population are similar to what has been observed on the entire population living in the four cities. ${ }^{9}$ Being alone (widow or not married), previous psychiatric and cerebrovascular disorders are strong risk factors as shown in the previous study, but unexpectedly there was no higher risk among women. Finally, acute heart failure (including changes of pulmonary circulation-that is, cor pulmonale), stroke and 
Table 3 Risk of dying on days with a mean apparent temperature of $30^{\circ} \mathrm{C}$ (lag $\left.0-1\right)$ versus days with a temperature of $20^{\circ} \mathrm{C}$ among people age $65+$ years who died in hospital and were already in hospital two days before death: effect modification by age and hospital ward

\begin{tabular}{|c|c|c|c|c|c|c|c|c|c|c|}
\hline \multirow[b]{2}{*}{$\begin{array}{l}\text { Ward of the } \\
\text { hospital }\end{array}$} & \multirow[b]{2}{*}{$\%$} & \multicolumn{3}{|c|}{ Age $65-74$ years } & \multicolumn{3}{|c|}{ Age $75-84$ years } & \multicolumn{3}{|c|}{ Age 85 +years } \\
\hline & & No & $\begin{array}{l}\text { OR } \\
\text { (95\% Cl) }\end{array}$ & $\begin{array}{l}\text { REM index } \dagger \\
\text { (p.value) }\end{array}$ & No & $\begin{array}{l}\text { OR } \\
\text { (95\% Cl) }\end{array}$ & $\begin{array}{l}\text { REM index } \dagger \\
(p \text { value })\end{array}$ & No & $\begin{array}{l}\text { OR } \\
\text { (95\% CI) }\end{array}$ & $\begin{array}{l}\text { REM index } \dagger \\
\text { ( } \mathrm{p} \text { value) }\end{array}$ \\
\hline General medicine & 56 & 11960 & 1.31 (1.14 to 1.50$)$ & $1.00(-)$ & 21334 & 1.39 (1.25 to 1.54$)$ & $1.00(-)$ & 20187 & 1.46 (1.27 to 1.68$)$ & $1.00(-)$ \\
\hline High-care & 6 & 2031 & $1.12(0.78$ to 1.60$)$ & $0.85(0.419)$ & 2472 & 0.98 (0.71 to 1.35$)$ & $0.71(0.046)$ & 1288 & $1.31(0.86$ to 2.00$)$ & $0.90(0.644)$ \\
\hline Intensive care & 11 & 4149 & $1.07(0.83$ to 1.38$)$ & $0.82(0.181)$ & 4919 & $0.92(0.73$ to 1.16$)$ & $0.67(0.002)$ & 1505 & $1.82(1.20$ to 2.77$)$ & $1.25(0.323)$ \\
\hline
\end{tabular}

${ }^{*}$ Odds ratio (OR) and 95\% confidence intervals (Cl). Results in italics are from random effects models.

$\uparrow R E M$, relative effect modification index is calculated as the ratio between the specific OR and the OR from the reference category (from the age-adjusted model).

exacerbations of chronic pulmonary disease are strong risk indicators of heat-related mortality.

From the study design adopted, it is clear that we have studied a selected group of high-risk patients. For elderly people at home, living conditions including availability of air conditioning, family, social and medical support, as well as presence of chronic comorbidities are likely to be the important modifiers of the effect of summer temperatures on mortality. In the case of hospitalised patients, the hospital and ward characteristics including availability of thermal comfort, quality of medical care, and severity of the acute clinical conditions are likely important risk indicators. Unfortunately, there are no official statistics on the availability of air conditioning in Italian health care centres. It is known, however, that most of the hospitals in the cities we have investigated did not have air conditioning at the time of the study, except for operating rooms and intensive care units. The increased risk of heat-related mortality in general medicine among 65-84-year-olds may be interpreted as the result of various factors, such as the absence of air conditioning in these wards, lower attention to the medical care needs of the patients and a specific case-mix (for example, heart failure, cerebrovascular diseases, and chronic pulmonary diseases, as indicated in the online table). However, we also found an increased heat-related mortality in intensive care units among individuals aged $85+$ years that cannot be simply explained by the most common acute medical conditions of these patients (for example, myocardial infarction). It should be noted that a study conducted in France during summer 2003 suggests that heat-related deaths may be observed in intensive care during heat waves, especially if air conditioning is lacking. ${ }^{20}$

Table 4 Risk of dying on days with a mean apparent temperature of $30^{\circ} \mathrm{C}(\operatorname{lag} 0-1)$ versus days with a mean apparent temperature of $20^{\circ} \mathrm{C}$ among people age $65+$ years who died in hospital and were already in hospital two days before death: effect modification by 26 groups of diagnoses figuring either as the primary or as a secondary contributing cause of hospital admission in the two years before death, excluding last four weeks

\begin{tabular}{|c|c|c|c|c|}
\hline Chronic conditions (ICD-9 code) & $\%$ & $\begin{array}{c}\text { OR (95\% Cl)* } \\
\text { (unadjusted) }\end{array}$ & $\begin{array}{l}\text { OR (95\% CI)* } \\
\text { (age-adjusted) }\end{array}$ & $\begin{array}{l}\text { REM index } \dagger \\
\text { (p value) }\end{array}$ \\
\hline \multicolumn{5}{|l|}{ Cardiovascular diseases } \\
\hline Diseases of valves (ICD-9: 394.0-397.1, 424, 746.3-746.6, 093.2) & 4.2 & 1.13 (0.77 to 1.65$)$ & $1.15(0.78$ to 1.70$)$ & $0.86(0.445)$ \\
\hline Previous acute myocardial infarction (ICD-9: 410, 412) & 5.7 & 1.24 (1.00 to 1.52$)$ & 1.21 (0.97 to 1.51$)$ & $0.90(0.365)$ \\
\hline Other ischaemic heart diseases (ICD-9: 411, 413-414) & 15.0 & 1.31 (1.19 to 1.49$)$ & $1.34(1.17$ to 1.53$)$ & $1.00(0.997)$ \\
\hline Diseases of pulmonary circulation (ICD-9: 415-417) & 2.3 & $1.06(0.74$ to 1.53$)$ & $1.09(0.70$ to 1.70$)$ & $0.81(0.352)$ \\
\hline Heart failure (ICD-9: 428) & 13.2 & $1.25(1.09$ to 1.45$)$ & $1.29(1.11$ to 1.49$)$ & $0.96(0.582)$ \\
\hline Cerebrovascular diseases (ICD-9: 430-438) & 16.5 & $1.49(1.32$ to 1.68$)$ & $1.50(1.32$ to 1.70$)$ & $1.15(0.063)$ \\
\hline Diseases of arteries, arterioles, and capillaries (ICD-9: 440-448) & 7.9 & $1.40(1.16$ to 1.68$)$ & $1.44(1.19$ to 1.75$)$ & $1.08(0.428)$ \\
\hline \multicolumn{5}{|l|}{ Respiratory diseases } \\
\hline Pneumonia (ICD-9: 480-486) & 7.4 & 1.34 (1.07 to 1.68$)$ & $1.32(1.09$ to 1.60$)$ & $0.99(0.934)$ \\
\hline Chronic pulmonary diseases (ICD-9: 490-505) & 15.0 & $1.23(1.07$ to 1.40$)$ & $1.24(1.08$ to 1.42$)$ & $0.92(0.281)$ \\
\hline Disorders of fluid, electrolyte, and acid-base balance (ICD-9: 276) & 2.0 & $1.13(0.69$ to 1.86$)$ & $0.94(0.63$ to 1.41$)$ & $0.70(0.091)$ \\
\hline Obesity and other hyperalimentation (ICD-9: 278) & 0.8 & $1.84(1.02$ to 3.31$)$ & $2.18(0.86$ to 5.50$)$ & $1.63(0.300)$ \\
\hline Anaemias (ICD-9: 280-285) & 10.6 & $1.25(1.07$ to 1.45$)$ & $1.27(1.09$ to 1.48$)$ & $0.94(0.472)$ \\
\hline Psychoses (ICD-9: 290-299) & 4.3 & 1.98 (1.43 to 2.74$)$ & 2.05 (1.44 to 2.93$)$ & $1.56(0.016)$ \\
\hline Depression (ICD-9: 300.4, 301.1, 309.0, 309.1, 311) & 1.1 & 0.99 (0.51 to 1.90$)$ & 1.24 (0.47 to 3.25$)$ & $0.92(0.874)$ \\
\hline Paralysis (ICD-9: $342-344)$ & 1.6 & $1.44(0.97$ to 2.13$)$ & $1.49(0.96$ to 2.30$)$ & $1.11(0.636)$ \\
\hline Other disorders of the central nervous system (ICD-9: $330-341,345-349$ ) & 5.5 & 1.61 (1.25 to 2.07$)$ & 1.58 (1.24 to 2.03$)$ & $1.20(0.162)$ \\
\hline Acute and chronic liver diseases (ICD-9: $570-572$ ) & 5.1 & $1.22(0.97$ to 1.54$)$ & $1.11(0.79$ to 1.57$)$ & $0.83(0.299)$ \\
\hline Renal failure (ICD-9: 584-588) & 9.6 & $1.29(1.10$ to 1.52$)$ & $1.33(1.13$ to 1.57$)$ & $0.99(0.955)$ \\
\hline Diseases of the osteomuscular system (ICD-9: 710-739) & 6.1 & $1.32(1.08$ to 1.62$)$ & $1.28(1.03$ to 1.59$)$ & $0.96(0.725)$ \\
\hline Hip fracture (ICD-9: 820-821) & 3.4 & $1.70(1.28$ to 2.24$)$ & $1.66(1.23$ to 2.25$)$ & $1.25(0.156)$ \\
\hline
\end{tabular}

${ }^{*}$ Odds ratio (OR) and $95 \%$ confidence intervals (Cl). Results in italics are from random effects models.

$+R E M$, relative effect modification index is calculated as the ratio between the specific $\mathrm{OR}$ and the $\mathrm{OR}$ from the reference category (from the age-adjusted model). 
Table 5 Risk of dying on days with a mean apparent temperature of $30^{\circ} \mathrm{C}$ (lag $\left.0-1\right)$ versus days with a mean apparent temperature of $20^{\circ} \mathrm{C}$ among people age 65+ years who died in hospital and were already in hospital two days before death: effect modification by nine groups of diagnoses figuring as the primary cause of the hospital admission two days before death

\begin{tabular}{|c|c|c|c|c|}
\hline Acute conditions (ICD-9 code) & $\%$ & $\begin{array}{c}\text { OR (95\% CI)* } \\
\text { (unadjusted) }\end{array}$ & $\begin{array}{l}\text { OR (95\% Cl)* } \\
\text { (age-adjusted) }\end{array}$ & $\begin{array}{l}\text { REM index } \\
\text { ( } p \text { value) }\end{array}$ \\
\hline \multicolumn{5}{|l|}{ Cardiovascular diseases } \\
\hline Acute myocardial infarction (ICD-9: 410) & 3.9 & $1.16(0.90$ to 1.51$)$ & $1.19(0.90$ to 1.56$)$ & $0.88(0.374)$ \\
\hline Cardiac dysrhythmias (ICD-9: 427) & 3.1 & $1.16(0.86$ to 1.57$)$ & $1.18(0.86$ to 1.61$)$ & $0.88(0.415)$ \\
\hline Heart failure (ICD-9: 428) & 5.9 & $1.66(1.33$ to 2.07$)$ & 1.69 (1.34 to 2.14$)$ & $1.28(0.047)$ \\
\hline Cerebrovascular diseases (ICD-9: 430-438) & 12.9 & $1.60(1.39$ to 1.85$)$ & 1.59 (1.37 to 1.84$)$ & $1.22(0.019)$ \\
\hline Chronic pulmonary diseases (ICD-9: 490-505) & 1.7 & $2.08(1.33$ to 3.26$)$ & $2.48(1.50$ to 4.09$)$ & $1.87(0.015)$ \\
\hline \multicolumn{5}{|l|}{ Other diseases } \\
\hline Acute and chronic liver diseases (ICD-9: $570-572$ ) & 2.2 & $1.03(0.67$ to 1.58$)$ & 1.21 (0.61 to 2.43$)$ & $0.90(0.776)$ \\
\hline Renal failure (ICD-9: 584-588) & 2.4 & $0.88(0.62$ to 1.24$)$ & 0.91 (0.64 to 1.31$)$ & $0.68(0.035)$ \\
\hline
\end{tabular}

${ }^{*}$ Odds ratio (OR) and $95 \%$ confidence intervals (CI).

$\uparrow R E M$, relative effect modification index is calculated as the ratio between the specific $\mathrm{OR}$ and the OR from the reference category (from the age-adjusted model).

The increased risk found among the single and widowed people, which is similar to what has been found in the previous study conducted on out-of-hospital deaths, ${ }^{9}$ indicates that family and social support may also be relevant for hospitalised patients. The lack of a family support may be associated with a more isolated hospital stay and a limited attention to individual requirements, including adequate fluid and electrolyte repletion. The attention on these aspects is usually under the control of hospital nurses who may not be in sufficient number or may lack appropriate instructions. Similarly, patients with psychiatric disorders and with a previous cerebrovascular accident, both requiring specific medical control, are more at risk of dying in the hospital during heatwaves, presumably because of inadequate medical care.

In order to discuss the specific results for the acute clinical conditions, some methodological aspects should be considered. As previously indicated, the case-crossover design is a powerful method to evaluate the effect of environmental variables and to test for effect modification. The extensive record linkage procedures of individual data from different sources offered us the opportunity to exploit individual information, a condition that is rarely available in environmental epidemiology. On the other hand, the quality of the clinical variables considered, based on hospital discharge files, suffers from a series of limitations. ${ }^{21}$ We have tried to increase the sensitivity of the definition of chronic conditions by using all the hospital admissions in the 29-day to 2-year period before death and considering both primary and contributory causes. The information is independent of the patient's final outcome and possible biases can be excluded. The study of the clinical conditions which characterised the subjects in the few weeks before death is more complex. The information from the last hospitalisation record was used, which in most of the cases coincides with the fatal outcome. In order to increase the specificity of the definition, the analysis was restricted to primary causes only. However, we cannot evaluate whether the acute clinical conditions actually precede the effect of heat (in other words are real effect modifiers) or if these conditions represent the ultimate cause of death due to heat stress.

Given the limitation indicated above, it is noteworthy that heart failure, stroke and chronic pulmonary diseases are associated with an increased heat-related mortality. The results for cerebrovascular diseases are not surprising since this is a condition that has been associated with heat exposure in clinical studies, and increased platelet, red cell counts and blood viscosity have been noted among volunteers exposed to heat. ${ }^{22} 23$ Moreover, it has been shown that body heat stress reduces baseline cerebral blood velocity and increases cerebral vascular resistance. ${ }^{24}$ Recent clinical evidence suggests that tolerance to heat stress may be impaired in patients with cardiovascular diseases, particularly those associated with impaired ventricular function and congestive heart failure as they exhibit attenuated

\section{What is already known}

Epidemiological research indicates that high summer temperatures are strongly associated with increased mortality in the general population. It is not known whether increase in temperature is associated with mortality among already hospitalised patients. Susceptibility factors of hospitalised subjects in relation to high temperatures are not known.

\section{What this paper adds}

- Temperature-related mortality is high among patients already hospitalised at the time of a heatwave.

- Elderly subjects and those hospitalised in general medicine wards are especially vulnerable.

- Acute heart failure, stroke and exacerbation of chronic pulmonary diseases are associated with an increased heatrelated mortality among hospitalised patients.

\section{Policy implications}

It emerges that the hospital care available does not provide sufficient protection to vulnerable patients, especially if they are hospitalised in general medicine and low-care wards. Better hospital conditions as well as more intensive health care for highrisk patients during the critical days of increased temperature may result in a significant health gain. 
cutaneous vasodilator responses to heating, a potential mechanism for heat intolerance. ${ }^{25}$ The extremely high risk found for patients with chronic pulmonary diseases is a new finding that requires further confirmation. These patients are likely to be admitted for an acute exacerbation, also for respiratory infection, and they generally have respiratory failure and are at high risk because of pulmonary hypertension and cor pulmonale. ${ }^{26}$ Increased mortality due to respiratory conditions during hot days has been described in several time-series studies. ${ }^{27}$ However, the specific mechanism among patients with chronic pulmonary diseases that confers such a strong vulnerability should be researched.

In conclusion, we have indicated that patients admitted to the hospital two or more days before relevant heat-stress conditions are at increased risk of dying in hospital wards because of extreme heat. It seems that the hospital care available does not provide sufficient protection for these patients, especially if they are hospitalised in general medical wards. Heart failure, stroke and chronic pulmonary diseases are associated with an increased heat-related mortality. Better hospital conditions as well as more intensive health care for high-risk patients during the critical days of increased temperature may result in a significant health gain.

Funding: partially supported by the Italian Department of Civil Protection (contract number: 491, 15/04/04).

Competing interests: None.

\section{REFERENCES}

1. Kosatsky T. The 2003 European heat waves. Eurosurveillance 2005;10:7-9.

2. Kovats RS, Ebi KL. Heat waves and public health in Europe. Eur J Public Health [online] 2006 Apr 27;0:ckl049v1. (http://eurpub.oxfordjournals.org/cgi/rapidpdf/ ckl049v1)

3. Michelozzi P, de'Donato FK, Accetta G, et al. Impact of heat waves on mortalityRome, Italy, June-August 2003. Morb Mortal Wkly Rep 2004;53:369-71.

4. Le Tertre A, Lefranc A, Eilstein D, et al. Impact of the 2003 heatwave on all-cause mortality in 9 French cities. Epidemiology 2006;17:1-5.

5. Johnson H, Kovats RS, McGregor G, et al. The impact of the 2003 heat wave on daily mortality in England and Wales and the use of rapid weekly mortality estimates. Euro Surveill 2005;10:168-71.

6. Michelozzi P, De Sario M, Accetta G, et al. Temperature and summer mortality: geographical and temporal variations in four Italian cities. J Epidemiol Community Health 2006;60:417-23.
7. De'Donato FK, Michelozzi P, Kalkstein L, et al. The Italian project for prevention of heat-health effects during summer, findings from 2005. In: Proceedings of the 17th International Congress of Biometeorology.Annalen der Meteorologie 2005;41:287-90.

8. Pascal M, Laaidi K, Ledrans $\mathrm{M}$, et al. France's heat health watch warning system. Int J Biometeorol 2006;50:144-53.

9. Stafoggia M, Forastiere F, Agostini D, et al. Vulnerability to heat-related mortality: a multicity, population-based, case-crossover analysis. Epidemiology 2006;17:315-23.

10. Watkins SJ, Byrne D, McDevitt M. Winter excess morbidity: is it a summer phenomenon? J Public Health Med 2001;23:237-41.

11. Klinenberg K. Heat wave: a social autopsy of disaster in Chicago. Chicago: The University of Chicago Press, 2002.

12. O'Neill MS, Zanobetti A, Schwartz J. Modifiers of the temperature and mortality association in seven US cities. Am J Epidemiol 2003;157:1074-82.

13. Ferron C, Trewick D, Le Conte $\mathrm{P}$, et al. [Heat stroke in hospital patients during the summer 2003 heat wave: a nosocomial disease]. Presse Med 2006;35:196-9.

14. Elixhauser A, Steiner C, Harris DR, et al. Comorbidity measures for use with administrative data. Med Care 1998;36:8-27.

15. Kalkstein LS, Valimont KM. An evaluation of summer discomfort in the United States using a relative climatological index. Bull Am Meteorol Soc 1986;67:842-8.

16. Maclure M. The case-crossover design: a method for studying transient effects on the risk of acute events. Am J Epidemiol 1991;133:144-53.

17. Levy D, Lumley $T$, Sheppard L, et al. Referent selection in case-crossover analyses of acute health effects of air pollution. Epidemiology 2001;12:186-92.

18. Van Houwelingen HC, Arends LR, Stijnen T. Advanced methods in meta-analysis: multivariate approach and meta-regression. Stat Med 2002;21:589-624.

19. Künzli N, Schindler C. A call for reporting the relevant exposure term in air pollution case-crossover studies. J Epidemiol Community Health 2005;59:527-30.

20. Misset B, De Jonghe B, Bastuji-Garin S, et al. Mortality of patients with heatstroke admitted to intensive care units during the 2003 heat wave in France: a national multiple-center risk-factor study. Crit Care Med 2006;34:1087-92.

21. Jollis JG, Ancukiewicz M, DeLong ER, et al. Discordance of databases designed for claims payment versus clinical information systems. Implications for outcomes research. Ann Intern Med 1993;119:844-50.

22. Keatinge WR, Coleshaw SR, Easton JC, et al. Increased platelet and red cell counts, blood viscosity, and plasma cholesterol levels during heat stress, and mortality from coronary and cerebral thrombosis. Am J Med 1986;81:795-800.

23. Donaldson GC, Keatinge WR, Saunders RD. Cardiovascular responses to heat stress and their adverse consequences in healthy and vulnerable human populations. Int J Hyperthermia 2003;19:225-35.

24. Wilson TE, Cui J, Zhang R, et al. Heat stress reduces cerebral blood velocity and markedly impairs orthostatic tolerance in humans. Am J Physiol Regul Integr Comp Physiol [online] 2006;0:00712.2005v1. (http://ajpregu.physiology.org/cgi/reprint/ $00712.2005 v 1)$

25. Cui J, Arbab-Zadeh A, Prasad A, et al. Effects of heat stress on thermoregulatory responses in congestive heart failure patients. Circulation 2005;112:2286-92.

26. Antonelli Incalzi R, Fuso L, De Rosa M, et al. Co-morbidity contributes to predict mortality of patients with chronic obstructive pulmonary disease. Eur Respir $J$ 1997; 10:2794-800.

27. Basu R, Samet JM. Relation between elevated ambient temperature and mortality: a review of the epidemiologic evidence. Epidemiol Rev 2002;24:190-202.

Find out automatically when an article is published on a specific topic or by a particular author. We can also alert you when an article is cited or if an eLetter or correction is published. You can also choose to be alerted when a new issue is published online [and when we post articles Online First]. Check out the New Content Alerts and Citation tracker from the Online tools section on the home page. 